\title{
The Commoditization of White Collar Work
}

\author{
Andrew Holmes, Partner, Paricint \\ No. 4, 19 Buckingham Street \\ London WC2N 6EG, United Kingdom \\ E-mail: Andrew.Holmes@paricint.com
}

John Ryan (Corresponding author)

Hult International Business School

46 - 47 Russell Square, London WC1B 4JP, United Kingdom

Tel: 44-795-176-5549 E-mail: JMTRYAN@AOL.CO.UK

\begin{abstract}
The next wave is already upon us, although it still has a very long way to run. White collar work is now well on the way to commoditization. The combination of an aging population, the increased codification of work through the standardization of processes, the increasing sophistication and scope and scale of IT systems and the availability of a cheap and well educated labour force from across the world means that much of the routine work that is now undertaken by well paid staffers will eventually be automated, outsourced, offshored or executed by less expensive personnel. Be warned, this is not just about the simple and routine activities undertaken by administrative personnel. As we will see later, most white collar work is potentially up for grabs, including lawyers, consultants and even surgeons. In fact, any work which does not require high level expertise has the potential to be commoditized.
\end{abstract}

Keywords: Commoditization, Demographic, Economic migration, Offshoring, White collar workplace

\section{Why now?}

First it is important to point out that the commoditization of white collar work is part of the natural progression. As the successive waves have moved up the value chain, it was only a matter of time before white collar work itself could be sufficiently codified to allow it to become commoditized. White collar work is now commoditizable for the following reasons:

- The impact of technology, especially in terms of the ability to take work out of the system

- The development and introduction of standards, standard operating procedures and the creation of standardized and hence commoditized processes

- The changing nature of employment and especially that which has occurred since the downsizing of corporations during the 1990s (more on this shortly)

- The changing demographic dynamics and the associated imbalances this causes within organizations (at the micro level) and nations (at the macro level).

Before moving onto the specific aspects of white collar commoditization and the types of activity that can be considered commoditizable, as well as those which could be considered immune, it is important to explore the changing nature of work the workplace factors, and the shifting patterns of demographic change - the population factors, in more detail.

\section{The workplace factors}

Any discussion about the commoditization of white collar work should address the changing nature of work and of the workplace in general because both have made it easier for employers to exploit the benefits associated with labour arbitrage. The workforce factors act as a foundation on which white collar commoditization can thrive because they set the tone, culture and the precedents which permit organizations to push the boundaries and limits of the employment relationship and ultimately the flexibility of its employees. There are four factors worth discussing:

- The changing nature of work and careers

- The end of the psychological contract and the eroding of the 1950's image of a job for life and the gold watch after 30 years of service

- The intensification of work resulting from the increased use of mobile and connected technologies 
- The reduction in work-based benefits, which is placing greater financial risk on the employee, especially in terms of retirement.

\section{The changing nature of work - the golden age is over}

Organizations have always been concerned about their competitiveness. Taking this seriously has meant developing the right products and services, recruiting and retaining the best talent and keeping an eye on the future to ensure they are appropriately positioned to meet the challenges ahead. In the past this was a relatively simple exercise because the economic backdrop was one of steady growth and relative stability, especially following the Second World War; long considered to be the golden age of employment. This stability led to the creation of benevolent and paternalistic organizational cultures that looked after their staff and pretty much managed their careers for them. Employees could turn up for work in the knowledge that unless they did something seriously wrong, they would be guaranteed a job for life. They were willing to place their future careers in the hands of their employers and as long as they did a solid day's work and kept their noses clean they would gradually move up the hierarchy over the course of their career. If they were very lucky they might even reach the board of directors.

It is clear that the nature of work has changed irrevocably and that the comfortable days of working with a single employer for 30 years and following a well-trodden career path are over. The business and economic environments are now more turbulent than they have ever been, with the long term cyclical patterns in the economy being replaced by uncertainty, unpredictability and short-term cycles. The current issues over energy supply, the ongoing war on terror and the US deficit are all adding to this uncertainty. This turbulence and unpredictability is increasingly reflected in our working lives. We now have to have to contend with information overload, heightened insecurity, reduced job tenure and the loss of the incremental steps that had previously defined our careers. In addition, the reduction in organizational hierarchies through downsizing has reduced the sources of power within the workplace, thereby making it more difficult to determine an effective and obvious path to the top.

Recent change in the workplace has arisen from the combined effects of globalization and the increasingly rapid advance of technology. One could not exist without the other. With this backdrop, organizations have to consider how they can remain competitive in a commercial environment with fewer constraints and increased competition. Many have responded by merging with, or acquiring, other organizations that were better placed to deliver a truly global service. Others sought out the cheapest labour with which to manufacture their goods, leading to a massive reduction in the manufacturing sectors of the industrialised world as work was transferred to the cheaper economies of the Far East, Central Asia and, more recently, China. With further advances in technology since the 1970s, globalization is increasingly facilitating the transfer of knowledge and ensuring white collar work follows blue collar work around the world. And, with the emerging economies of Asia providing a ready supply of well-educated cheap labour, corporations are beginning to source their knowledge workers from overseas rather than at home, especially for those roles that do not require high levels of face-to-face contact.

\section{The end of the psychological contract}

For decades technology just affected blue-collar workers; office workers were mainly immune. They could sit in their warm offices pushing paper around their desks, attending important meetings and developing ideas and strategies for their companies in the knowledge they were far too clever or too important to suffer the same fate as their blue collar compatriots. The 1990s reengineering revolution put paid to that, as it stripped millions of office workers of their jobs, especially middle and senior managers. Although the impact was devastating for the many affected the increase in unemployment amongst the mid-career middle managers was largely offset and hence invisible within unemployment statistics by the return to work of so many wives, many of whom were forced back into work to provide some stability to the household balance sheet. This has been highlighted by a number of observers, who claim that this shift is creating a double income trap for many married and co-habiting couples.

Downsizing destroyed much of the cultural glue that held organizations together. It has resulted in the contract between employer and employee becoming too one-sided. Instead of being balanced with the employer offering security in exchange for commitment and responsiveness, it has become one in which the employer still expects commitment and flexibility, but only offers insecurity in return. Although one sided, staff are more likely to show less loyalty to their employer, as when employment markets are tight, staff are more likely to change jobs than remain where they are; something confirmed by the Society for Human Resource Management. They found that 83 per cent of employees were extremely or somewhat likely to search for a new job when the economy is high performing. There is no doubt that individuals increasingly see themselves as having a series of transactions with their employers and recognise that it is they, not their employers that have to manage their own careers - however they define them. This is a real break from the past, when people were content to stay where they were and were less likely to take some risk by moving companies. What is of greater concern to employers is that employees are generally less committed and apart from those at, or near the top, are no longer willing to go that extra mile, especially when they see little in the way of rewards for the extra effort. Over time this breeds mediocrity and lower performance which can have significant impacts on the bottom line because employees turn up for work, switch off and do the bare minimum to get the job done.

This loss of the strong bond between employer and employee has affected both organizations and staff alike. No longer 
comfortable and cohesive places that encouraged loyalty and commitment the working environment has become one of fear and distrust with a culture of self-interest and self-preservation. Fear rules the roost for many employees; always looking over their shoulders to see if they will be the next to face the axe. Unwilling to speak out, drive forward controversial ideas or raise risks, employees are more likely to keep their mouths shut, tow the party line and keep their heads down.

\section{The intensification of work}

The combined effect of technological change and globalization has resulted in the significant intensification of work which is far less positive because it serves to create new bad jobs. Intensification is evidenced by the increasing hours people are working and the degree to which work now spills over to leisure time, often referred to as job spill. Longer working hours is a common problem across the Western economies and increasingly the Eastern economies and results from the heightened insecurity that has come with downsizing and more recently outsourcing and offshoring. Americans are working longer and harder than ever before - 25 million now work more than 49 hours a week, with a large number working a lot more besides; 11 million spend 60 hours or more at work. The same is true for the United Kingdom which has the longest working hours in Europe; 91 per cent of British managers now work more than their contracted hours. No one is immune; in working couples nearly 46 per cent of men and 32 per cent of woman work more hours than they would like to. Of course, longer working hours is not a purely a Western phenomenon, as they are increasingly evident elsewhere, especially within Indian call centres, where 10 to 14 hour workdays are typical. But when compared to China, all this pales into insignificance. Consider what happens at one of China's largest telecom manufacturers; every employee is issued with a mattress so that they can grab a nap beneath their desks, day or night, when they are overcome by exhaustion from their excessive working hours. This is euphemistically known as the mattress culture by the workers. Rolled up to the national level and things start to look grim as up to one million Chinese die every year from overwork. And, unlike in the West, all sectors of the economy are subject to overwork, even the cosy and rarefied world of academia, where 135 professors and other academic staff have died from overwork in the past five years.

The problem is that longer working hours both inside and outside of work means that there is less time to relax. With work spilling over to weekends and evenings, white-collar workers are finding themselves squeezed with little or no time to unwind and recover from the working day. The traditional patterns of working life have changed so much, that for many it is virtually impossible to distinguish between the office and the home. Vacations too are being reduced through cost cutting initiatives by organizations as they struggle to remain competitive and by employees who believe they are too busy or too important to take them. And for many the office and their work schedule travels with them. It is not uncommon for executives to conduct teleconferences from the beach or poolside, and take their laptops on holiday so that they can deal with urgent issues and emails.

Indeed, with less time to relax workers are experiencing increasing levels of stress and increased health and safety concerns. Modern 24/7 workplaces put more employees at risk from health problems such as high blood pressure, cardiovascular disease and alcoholism. Stress is a way of life for many white-collar workers irrespective of age or position within the corporate hierarchy.

\section{Where have the benefits gone?}

The final workplace factor to consider is the reduction in benefits from employers as they pursue shareholder value, seek ways to continue to drive up profits and reduce the long term burden of looking after an aging workforce who may spend longer in retirement than they did in work. Therefore at the same time as expecting more from their employees, employers are scaling back the rewards they provide and people are earning less not more. Middle income families in America saw their income rise by just $\$ 780$ between 1988 and 1998, and although median income for US households increased by 1.1 per cent to $\$ 46,326$ in 2005 , earnings fell for both full time working men and women by 1.8 and 1.3 per cent respectively. The increase in income was masked by people juggling more than one job and the drop highlights a concern that the US economy is not generating sufficient high paying job. Indeed, if you take into account where the bulk of the jobs are being created, you can see why; the increase in employment has not been at the top end. Far from it, most of the new jobs have been in low end service economy companies, where wages are low and opportunities limited.

- Food preparation

- Waiters and waitresses

- Janitors and cleaners

- Nursing aides, orderlies and attendants

- Cashiers

- Customer service representatives

- Retails salespersons

- Registered nurses

- General and operational managers

- Postsecondary teachers. 
In the United Kingdom and increasingly elsewhere, companies are cutting back on pension provision as they close down their defined benefits schemes (in which the final salary and number of years of service are used to calculate the pension that will be paid to the employee on retirement and until death) and replace these with defined contributions schemes (in which both the employer and employee contribute to a pension fund whose value at retirement depends on the level of contributions and the performance of the stock they purchase with the premiums). Every week there is another headline regarding the termination of defined benefits schemes. Even for those companies that choose to keep their defined benefits schemes open they tend to water down the benefits by using the average salary over an employees' career to calculate the pension and increasing the age at which the benefits can be taken. They also expect employees to pay more into the scheme and penalise them if they take early retirement.

\section{Demographic factors}

Whilst the impacts of the workplace factors are significant, interest in the commoditization of white collar work would not be as high if it were not for the more fundamental factors associated with the demographic changes playing out across the globe. The world's population is changing and fast: as the West declines into its old age, the East moves into adolescence and early maturity. The complementary spirals one down and the other up, is acting as an accelerator to commoditization. The principal factors worthy of discussion here are:

- The aging of the West

- The resurgence of the East

- Economic migration.

\section{The aging of the West}

The longevity of the human race has been increasing ever since we left the caves. During the Palaeolithic period life expectancy was typically 25 years and once the high death rates associated with babies and children had been stripped out this could be between 30 and 40; by 1725 this could be as high as 50 if you lived in the healthier conditions of North America, although the average was still only 32 and by 1900 Europeans could expect to live to the ripe old age of 48 . This gradual increase changed during the latter half of the $20^{\text {th }}$ century when by 1950 people could expect to be still around at 68 and by 199077 was the average age at death. The result, which had rarely been a problem in the past, is that the populations of the industrialised world are growing older at an alarming rate. The bulge of the 1960's baby boom and the secondary boom that began in the mid 1970s and peaked in 1990 is hurtling towards retirement.

This would not be such an issue if it wasn't for the corresponding reduction in birth rates which are, in many western countries below replacement levels. This fall is significant if only for the simple reason that rising populations in the West have for so long equated to prosperity - the gross domestic product (GDP) of any nation is equal to the sum of its labour force times the average output per worker. When populations fall, GDP falls unless productivity increases to compensate. This is why organizations take such a keen interest in the application of technology and governments in attracting intelligent migrants. It is clear that something has to change if the high level of prosperity that the West has enjoyed for long is to be sustained.

This double bind of aging populations and falling birth rates is causing enormous concern in Western economies:

- In the United Kingdom the number of people under 18 will fall from 7.0 to 6.6 million between now and 2011. At the same time the proportion aged 60 and over will increase from 12.1 to 14.0 million

- Unless Japanese women begin to have more children, the population is expected to shrink by 20 per cent by the middle of the century. The problem is now so critical that the Japanese have a name for it - "shoshika" which means a society without children

- For the last ten years Germany's birth rate has been below replacement levels. This will result in the population falling from 82 million to 59 million over the next 50 years and a third of this will be over 65 . This is being further compounded by the departure of its qualified workers as they pursue better opportunities outside of Germany

- In June 2000 the Organization for Economic Cooperation and Development (OECD) forecast that the ratio of elderly (those aged over 65) to those of working age (those between the ages of 20 and 64) would nearly double in the next 50 years

- The European Commission projects that Europe's potential growth rate over the next 50 years will fall by 40 per cent due to the shrinking size of the workforce. And within 50 years there will be 100 million fewer people living in Europe. Worse still, even if Europe can attract 600,000 new immigrants every year its population will still decline by 96 million, and if it can't, by 139 million.

It is clear that all industrialized countries are destined to experience similar problems as birth rates continue to fall. But it also seems that such falls in birth rate are no longer restricted to the industrialized world. Recent United Nations data suggests that the developing world is following in the West's footsteps, with families choosing to have fewer and fewer children in return for greater economic prosperity (and consumption). With birth rates across the world expected to fall below replacement levels over the next few decades, the world's population is predicted to peak at 8 billion and then start to fall in the second half 
of the 21 st century. Some believe that the world's population will halve within 150 years. Take the UK's power and water infrastructure. Plans to enhance and maintain this over the next 10-15 years are at risk due to the imminent retirement of many of the most experienced members of the utility sector. Although the retirement of engineers with up to 20 years of experience is bad for the industry, this is exacerbated by the limited number of engineering graduates coming though the system and the poor salaries they are paid compared to those offered within the financial services sector.

This issue is particularly acute when we consider how hard it is to change an older workforce. According to the authors of Workforce Crisis, organizations will have to become better at managing and motivating the broad spectrum of employees they will have to employ. In their analysis, they focus on three cohorts: the baby boomers, where retirement or old age employment is a pressing concern, the generation X-ers who are mid-career, bored, stressed out, or just plain tired and the millennials who want everything their own way. Each group presents their own unique motivational concerns which have to be dealt with.

\section{The resurgence of the East}

Just as the West slides into old age, the East is beginning to pick up the pace and return to the position of global dominance they once held. Although some Asian nations face the same aging problems as the West, most notably Japan and increasingly China, the majority have considerably more youthful populations. It is this youth that is providing the platform for growth and the necessary energy to pick up where the US and Europe are expected to leave off. Many Asian countries are completing the political, social and economic reforms that followed the end of World War II. Previously, social norms, the influence of communist regimes or similar draconian state dominance, and Western (mainly American) control prevented the Asian economies from expanding. The changes taking place are enabling the Asian economies to develop their own approaches to commerce and their own flavour of trade and ambition.

2005 was a milestone in global terms as it was the year when the combined outputs of the emerging economies accounted for more than half of the total world gross domestic product which means that the developed nations are no longer dominating the global economy. And although American companies initially led and dominated globalization, they are no longer the leaders they once were. The emergence of multinational companies from within China, India, Brazil and Russia are changing the very nature of the global economy as they shake up entire industries. What makes many of these companies different from their earlier counterparts from Korea and Japan is that they have had to learn to survive in a highly competitive and cutthroat environment, unprotected by government subsidies and protectionist policies (unlike their counterparts in the West). This has meant seeking out margins at prices that would never be sustained in the West. For example Indian drug manufacturers' charge as little as one per cent of what people pay in the US for their generic drugs. Others such as the Chinese Lenovo Group are big enough to buy those parts of western companies that are no longer considered profitable, as they demonstrated when they bought IBM's PC making business in 2005 for $\$ 11$ billion. Sector leaders, so long based in the US and Europe are now being superseded by companies such as Tata Consultancy Services (technology), SAB Miller (brewing), Embraer (aircraft manufacturing), América Móvil (telecoms), CNOOC (oil and gas) and Sadia (food and drink).

Although their principal advantage lies in the low labour costs, there are other factors working in their favour including a larger pool of labour from which to draw their staff, a keener workforce who sees economic gain from working with prestigious multinational companies and a strong innovative streak. Unsurprisingly, the Eastern economies are considering clubbing together to create their own trading bloc which will rival NAFTA (the North American Free Trade Agreement) and the EU (European Union) - see Table 1.

The free-trade idea is being spearheaded by the Japanese who are promising a ten billion Yen ( $\$ 95$ million) study to assess how it will work. The goal is to have the trading bloc up and running by 2015 and when fully functioning is expected to increase the total economic output of its members by $\$ 215$ billion.

\section{Economic migration}

According to the World Bank's latest Economic Prospects report, the pressure for migration from poor to rich countries is a permanent feature of our integrating world. The share of migrants in the populations of high-income countries has risen from 4.4 per cent in 1960 to 11.4 per cent in 2005.

Such sustained levels of economic migration are creating significant tensions in the host nations including difficulties associated with social integration, the increasing number of illegal immigrants, and the problems the unskilled face as their jobs are taken by immigrants who are willing to work for less pay in order to gain a foothold in the economy. When you consider the significant disparities in incomes between the home and host nations, it soon becomes obvious why the immigrants want to move to the industrialised economies. Take Mexicans, who are coming to America in greater numbers than ever before. With 40 per cent of Mexico's 106 million people earning less than $\$ 2$ a day, the minimum wage of $\$ 41$ a day in the United States looks very attractive and presents a massive increase in income and standard of living.

Economic migration has traditionally focused on the lower end of the economy. As economies grow and move away from blue collar to white collar work, the desire to undertake the lower forms of employment drops; people don't want to be a server in a fast food restaurant for a few bucks an hour and would rather claim unemployment benefits, where they are often better off. Migrants however, are more than willing to do such work because it provides them with a chance to get a toehold in the 
economy and provide for their families back home. This highlights a major problem for many mature economies - what to with the unskilled, who are increasingly being alienated and pushed to the periphery of the economy.

In the modern economy a lack of skill is a major impediment to finding work and despite the strength of the economies in the US, UK, Germany and Canada, unemployment is rising. In part this is due to the high levels of economic migration, which includes not just the skilled migrants but also the uneducated. It also is also due to the shift to other forms of labour which require brains not brawn. Figures released by the US Labor Department shows that the unemployment rate for those who received education below senior high was 6.5 per cent in November 2000 but in January 2003 this had risen to 9.2 per cent. It is unlikely that this trend will end any time soon. And it will continue to increase the numbers of working poor in the United States, which currently stands at 37 million, a number which represents 12.7 per cent of the population and is the highest percentage in the industrialised world.

There has also been plenty of press coverage concerning the lack of workplace skills, which includes basic maths and English, of both school leavers and graduates. Some believe that the education system is dumbing down our future workers and because of this fewer are leaving school and university with the requisite skills necessary to deal with increasingly global and complex working environments. Whatever the arguments for or against this perception, it is clear that organizations in countries such as Germany, the United Kingdom, America, Canada and others will continue to experience massive shortfalls in both the number and quality of employees. With insufficient home grown talent, many have little choice but to look elsewhere and many may have no choice but to consider their workers a commodity which is traded and used like any other.

\section{Implications and responses - the rise of the commoditized workforce}

Dealing with the combined effects of the changing nature of work and attitude towards it as well as the shifts in the demographic composition of society and hence work is not easy. But what is clear is that the economic dominance of the West and East is shifting as downward mobility in the former is beginning to lose ground to the upward mobility of the latter (Figure $1)$.

Downward mobility, where the living standards of the workforce reduce over time, was first identified during the layoffs that came with the waves of downsizing that hit corporate America and Europe during the 1980s and 1990s. These days it is less publicised but more prevalent and no longer restricted to the working class, as middle class professionals often find themselves in this difficult position. The downwardly mobile often themselves on reduced incomes following a forced closure, redundancy or shift to an outsourcer and this is often accompanied by an inability to find a new role that meets their expectations both economically and from the perspective of work content. According to one analysis wage loss due to displacement is significant and persistent. Contrast this with the upward mobility of the East where incomes were and still are very low by western standards, but for many are rising. For the workers moving into a white collar job, even if it entails the near sweatshop conditions of a call centre, it represents a significant step up the career ladder which brings with it high rewards and benefits. For example, an Indian call centre employee may only earn $\$ 300$ a month, a fraction of the $\$ 3,000-\$ 5,000$ earned by someone in the US, but the earnings are so good that they are considered wealthy and socially mobile.

Another factor which is also impacting the degree to which downward and upward mobility is taking hold is the supply and demand of an educated workforce. With the Supply of graduates in the west now outstripping demand, the bachelor degree is fast becoming the new high school diploma and, like the holders of non-tertiary qualifications, those with just a degree are no longer capable of maintaining a comfortable lifestyle. At the same time the masters degree is taking the place of the bachelors degree and it is only the super-educated (often those with PhDs) that have any chance of a full and satisfying career. This is reflected in the number of students following advanced degrees, such as MBAs, which has grown considerably, more than those taking bachelor degrees -58 per cent compared to 25 per cent. Ironically, with so many now pursuing MBAs their value is decreasing and the knowledge advantage is eroding as every MBA programme teaches exactly the same thing, which implies that the head start that knowledge once gave us is shrinking. The median annual earnings of graduates and post graduates have declined. In 1972 a male holding a graduate or post graduate qualification earned a median income of $\$ 52,087$ (the female equivalent was $\$ 36,850$ ) and in 2002 this had dropped to $\$ 48,955(\$ 40,021)$. One of the reasons why incomes are dropping is the changing nature of the work available to graduates, which as we saw earlier is increasingly within the service sector. But there are three other reasons. The first is that economic migration and the effect of globalization in general has generated a downward pressure on the incomes of all but the most talented. A study by Harvard University confirmed this and showed that immigrant labour has reduced the wages of Americans performing low-skilled jobs by 7.4 per cent. When you consider that more than one billion unskilled, low-paid workers have entered the workforce over the recent past, this shouldn't come as much of a surprise. The second, as mentioned above, is that that there are just too many graduates chasing too few jobs that genuinely require graduate level skills. It is clear that the combined effects of technology, process standardisation and the competition coming out of the Indian subcontinent and China is reducing the need for home-grown graduates. With Indian graduates costing approximately 12 per cent of their American counterparts the economic impact is obvious. But then if you factor in the number of hours they work (2,350 hours per year against 1,900 for the American) you can buy almost ten Indian graduates for the price of one American. The third reason is that there are not enough science and technology graduates - the 
right type of graduate. Although the number of graduates may be increasing, those with core science and technology subjects are decreasing and it is this that is worrying organizations and policy makers both sides of the Atlantic. The Confederation of British Industry likens this to a "car crash in slow motion". Indeed the lack of graduates is already forcing some companies to move offshore.

Contrast this with what is happening in places like India and China who are churning out huge numbers of graduates, many of which have core science and technology backgrounds. Between them, India and China produce one million engineering graduates a year compared with the 170,000 produced by the US and Europe combined, and 2.8 million Chinese students graduate every year. Chinese and Indian graduates are also more willing to relocate to anywhere around the world which makes them the largest offshore talent pool available to any organization struggling to attract and retain the skilled personnel it needs to compete. Companies such as GE, SAP and Google have launched Chinese and Indian research centres to tap into this highly intelligent community but without the high costs associated with creating something similar in the US.

This brings us to the point where the argument for commoditization becomes a very strong one. With skills and capability gaps becoming more prevalent in the West, despite the increasing number of workers with degrees, and a surfeit of skilled graduates in the East the ability to source intelligent workers from overseas either through mechanisms such as outsourcing and offshoring or through economic migration is providing a solid platform from which white collar work can be commoditized. As the Eastern economies mature and move into the service and knowledge industries, the requirement to pay large salaries to American, British or European staff will, at least from a purely economic standpoint, no longer be necessary. Anyone wanting to pursue a productive career must now be willing to participate in the international economy regardless of their home country or employer. The only fly in the ointment is the recent trend for the overseas graduates, who have been educated in the top universities of America and Europe, to return home to pursue better and more exciting opportunities. The West is fast becoming a net exporter of the intellectual capital on which the future success of their economies depends. If this continues, the economic problems associated with an aging workforce will only get worse.

\section{Offshoring white collar work}

Companies offshore for a number of reasons, including:

- Taking advantage of lower labour costs found elsewhere in the world

- Transferring work which their employees are unwilling to do

- Accessing other markets; taking advantage of a 24/7 working model, which uses the three main time zones of the US, Europe and Asia

- Using unique skills which cannot be sourced within the home country.

Although once restricted to blue collar work, outsourcing and offshoring is increasingly affecting traditional white collar work and high-value jobs such as those associated with IT, accountancy, law, engineering design, medical diagnosis, finance and business consulting. It is predicted that up to $\$ 151$ billion in wages will be shifted from the US to the lower wage countries by 2015 and 550 of the 700 service job categories in the US will be affected in one way or another. Household names like Ford, General Electric, General Motors, Accenture, American Express, AOL, Apple, Bank of America, Boeing, Cisco Systems, Coca-Cola Goldman Sachs, Hershey, Johnson \& Johnson, Kellogg, Kimberly-Clark, Office Depot and Pfizer are exploring and exploiting offshoring. It is clear from this list that offshoring is affecting many organizations and it will, over time, affect many more. Pick up any newspaper any you will read about the latest trend of shipping out highly paid office work to other countries:

- To provide better value for money for its licence fee, the BBC is considering shifting support jobs - in essence, Human Resources, IT and finance offshore to locations such as India to cut costs. At the same time it is spending more and more on its most talented employees

- Medical records and patient diagnoses are increasingly being sent over to India where they are transcribed and sent back as documents to be inserted into the patient's medical file by the time the doctor starts his next round

- In response to rising costs mortgage companies are starting to offshore much of the basic processing and administration to India. It is believed that between 50 and 80 per cent of mortgage related work can be offshored.

Alan Blinder, an economist at Princeton University believes that the majority of economists are underestimating the disruptive effects of offshoring and that at least two to three times as many service jobs will be at risk. This implies that perhaps up to 30 per cent of jobs could be offshored. Of greater interest however is that it is the middle ranking jobs and professions that are most at risk. The offshoring of this type of work has a tendency to shift relative labour demand away from the medium- and high-skill worker towards low-skill workers. So while white collar offshoring is still small when compared to the offshoring of manufacturing, its bias against the skilled worker is a worrying trend. The top end and bottom end of the jobs spectrum are largely immune from offshoring; after all you cannot offshore a cab driver. Any job which can be standardized is being squeezed the hardest by offshoring. 
For now at least outsourcing and offshoring is creating a clear division of labour. For those who undertake routine and repetitive tasks it is highly likely that their work will be transferred to the lower wage economies of the world. With improved technology and increasing bandwidth it is just as easy for someone in India or China to complete a routine task as an American, Britain or European. This includes routine work associated with law, engineering, IT and many others. It's unfortunate but anyone who works in this manner is on the path of downward mobility. For those who perform non-routine, creative or innovative tasks, such as research scientists, financiers, marketers and architects, the offshoring trend will pass them by; for now at least. However, as technology and standards continue to routinize work and the number of intelligent science and technology graduates from China and India increase, this comfortable position may well change.

\section{References}

Andresky Fraser, J. (2001). White-Collar Sweatshop: The Deterioration of Work and Its Corporate America. New York: W.W. Norton and Company, p. 3-74.

Benoit, B. (2006). Economy set to feel the strain as German exodus gains momentum. Financial Times, (September 2/3), 5.

Bolger, J. (2007). Utilities fear for future as engineers head into retirement. The Times (April 10), 37.

Bonner, B. (2006). The Earth is not flat: why the rich get richer. Money Week (March), 25.

Bosshart, D. (2007). Cheap? The real cost of living in a low price, low wage world. London: Kogan Page, p. 24.

Buchanan, P (2002). The death of the West: How dying populations and immigrant invasions imperil our country and civilization. New York: Thomas Dunne Books, St Martins Press, p. 14.

Buchanan, P. (2006). State of Emergency. New York: Thomas Dunne Books, p. 33.

Buchanan, P. (2006). State of Emergency. New York: Thomas Dunne Books, p. 121.

Budden, R. (2006). Employers' tweaking of final salary schemes waters down the benefits. Financial Times, (September 2/3), Money section, p. 8-9.

Bunting, M. (2004). Willing Slaves: How the Overwork Culture is Ruling Our Lives. London: HarperCollins Publisher, p. 7.

Cauchon, D. (2006). Family income up, but not pay. USA Today (August 30), 1A.

Di, G. (2006). Do not blame China for job losses in US. China Daily 9th May Available: http://www.chinadaily.com.cn

Dobbs, L. (2004). Exporting America: why corporate greed is shipping American jobs overseas. New York.

Draut, T. (2006). Strapped: Why America's 20- and 30- somethings can't get ahead. New York: Doubleday, p. 54.

Draut, T. (2006). Strapped: Why America's 20- and 30- somethings can't get ahead. New York: Doubleday, p. 80.

Eaglesham, J. (2006). CBI warns of drop in science graduates. Financial Times (March 15), 2.

Engardio, P. (2006). Emerging Giants. BusinessWeek (July 31).

Gluckman, P., \& Hanson M. (2006). Mismatch: why our world no longer fits our bodies. Oxford: Oxford University Press, p. 178.

Gluckman, P., \& Hanson M. (2006). Mismatch: why our world no longer fits our bodies. Oxford: Oxford University Press, p. 178.

Home and away. (2006). The Economist (October 7), 82.

Ibid, p. 33. Ibid. p. 167-196.

Longman, P. (2004). The Empty Cradle: How Falling Birthrates Threaten World Prosperity [and what to do about it]. New York: New America Books, p. 41.

O’Toole J., \& Lawler, E. (2006). The New American Workplace. New York: Palgrave Macmillan, p. 197.

OECD. (2007), Employment outlook, p. 129-130.

Overell, S. (2005). Stress hits India's outsourced and overworked. Financial Times (July 8), 12.

Reilly, P. (2001). Flexibility at work: balancing the interests of employer and employee. Aldershot: Gower, p. 78.

Schrage, M. (2006). The Asian giants and the brains bazaar. Financial Times (May 15), 17.

Sheppard, N. (2004). The commoditization of Populations, Available: http://www.intellectualconservative.com

Sheppard, N. (2004). The commoditization of Populations, Available: http://www.intellectualconservative.com

Terazone, E. (2006). BBC considers shifting jobs offshore. Financial Times (July 8/9, 2006), 3. 
The battle for brain power: A survey of talent. The Economist (October 7), p. 4.

The battle for brain power: A survey of talent. The Economist (October 7), p. 9.

The Henley Centre. (2007).

Uchitelle, L. (2006). The Disposable American. New York: Alfred A. Knopf, p. 157.

Uchitelle, L. (2006). The Disposable American. New York: Alfred A. Knopf, p. 163.

Warner Business Books, p. 92.

Wolf, M. (2006). Why immigration policy has to be a compromise. Financial Times (December 22), 15.

Woodall, S. (2006). The new titans, A survey of the world economy. The Economist (September 16), 3.

Woodall, S. (2006). The new titans, A survey of the world economy. The Economist (September 16), 16-17.

York, G. (2006). A culture of overwork exacts an extreme price. The Globe and Mail (August 21), A2.

York, G., (2006). Asian trade bloc will rival Nafta, EU. The Globe \& Mail (August 24), B12.

Table 1. Trade blocs

\begin{tabular}{|c|c|c|c|}
\hline & Asian & NAFTA & $\mathbf{E U}$ \\
\hline Members & $\begin{array}{l}\text { Japan, China, South } \\
\text { Korea, New Zealand, } \\
\text { Brunei, Cambodia, } \\
\text { Indonesia, Laos, } \\
\text { Malaysia, Myanmar, } \\
\text { Singapore, Thailand, the } \\
\text { Philippines, Vietnam }\end{array}$ & $\begin{array}{c}\text { Canada, United States, } \\
\text { Mexico }\end{array}$ & $\begin{array}{l}\text { Austria, Belgium, Cyprus, } \\
\text { Czech Republic, Denmark, } \\
\text { Estonia, Finland, France, } \\
\text { Germany, Greece, Hungary, } \\
\text { Ireland, Italy, Latvia, } \\
\text { Lithuania, Luxembourg, } \\
\text { Malta, Poland, Portugal, } \\
\text { Slovakia, Slovenia, Spain, } \\
\text { Sweden, the Netherlands, } \\
\text { United Kingdom }\end{array}$ \\
\hline Population & 3.1 billion & 430.5 million & 460.1 million \\
\hline Combined GDP & $\$ 10$ trillion (US) & $\$ 12.9$ trillion & \$11.7 trillion \\
\hline
\end{tabular}

- Old and declining populations

- Below replacement level birth rates

- Dearth of the "right" graduates

- High workforce costs

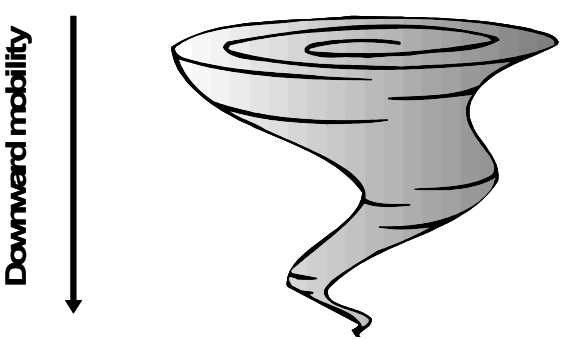

The West

\section{The East}

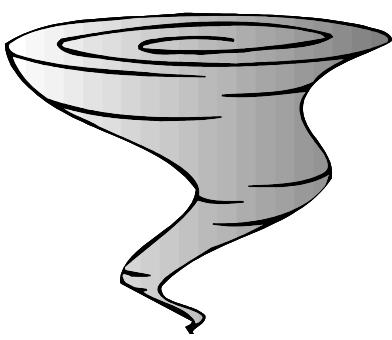

- Young and expanding populations

- Above replacement level birth rates

- Surplus of the "right" graduates

- Low workforce costs

Figure 1. Changing fortunes 